\title{
Suppressing the oxidation of LDL and DNA strand breakage of bioactives in dehulled and hull fraction of lentils
}

\author{
JuDong Yeo and Fereidoon Shahidi*
}

\begin{abstract}
Department of Biochemistry, Memorial University of Newfoundland, St. John's, NL, Canada A1B 3X9
*Corresponding author: Fereidoon Shahidi, Department of Biochemistry, Memorial University of Newfoundland, St. John's, NL, Canada A1B 3X9. Tel.: +1 709864 8552; E-mail: fshahidi@mun.ca
\end{abstract}

DOI: $10.31665 / \mathrm{JFB} .2020 .12250$

Received: October 29, 2020; Revised received \& accepted: December 23, 2020

Citation: Yeo, JD., and Shahidi, F. (2020). Suppressing the oxidation of LDL and DNA strand breakage of bioactives in dehulled and hull fraction of lentils. J. Food Bioact. 12: 122-128.

\begin{abstract}
Hull/seed coat contains various plant cells that are responsible for sustaining the life of seeds in which phenolics perform significant roles in supporting their functions. In the present study, inhibitory activities against the oxidation of LDL and DNA of soluble- and insoluble-bound phenolics in the dehulled and hull fractions of lentils were determined. In addition, their $\alpha$-glucosidase inhibitory activity was also assessed. The hulls possessed much higher levels of phenolics in both the soluble- and insoluble-bound forms than dehulled grain fractions, and this led to their potent activities in suppressing the oxidation of LDL and DNA and inhibiting $\alpha$-glucosidase activity. The high bioactivities of hulls might be due to the existence of various types of cells such as palisade and parenchyma cells containing numerous phenolics for sustaining their functions. This study may help in a better understanding of the localization of soluble- and insoluble-bound phenolics in the structure of lentil.
\end{abstract}

Keywords: Lentil; Seed coat; Phenolics; LDL oxidation; DNA scission.

\section{Introduction}

Lentils are valuable dietary sources of proteins, carbohydrates, minerals, vitamins, and dietary fiber (Rochfort and Panozzo, 2007). Moreover, they contain many health-promoting compounds such as phenolics, which are responsible for bioactivities such as anticancer and anti-hepatitis $\mathrm{C}$ virus (HCV), as well as reducing diabetes and cardiovascular disease (Hsu et al., 2015; Morgan et al., 2013; Narasimhan et al., 2015; Eitsuka et al., 2014; Mancuso and Santangelo, 2014).

In their structures, legumes mainly consist of hull/seed coat and dehulled grain parts. The hull fraction consists of several types of plant cells such as epidermis, hypodermis, chlorenchyma, palisade, parenchyma, and endothelium cells. These cells have various phenolic-containing organs such as vacuole and cell wall, thus the high level of phenolics in both soluble- and insoluble-bound forms are found in the hulls of legumes. On the other hand, the dehulled grain parts are primarily composed of the nutrition-storage cells such as the endosperm, hypocotyl and radicle, containing a high amount of lipids, proteins, and starch granules, leading to a low level of phenolics compared to the hulls (Figure 1).

Insoluble-bound phenolics are abundant in cereals, legumes, and seeds. They are responsible for the rigid structure of the cell wall by their association via covalent bonding to macromolecules such as cellulose, pectin, and structural protein. This association is through ether, ester, and covalent bonds. Cereals, legumes, and seeds contain a high proportion of insoluble-bound phenolics accounting for $20-60 \%$ of their total phenolics, while fruits and vegetables have a relatively lower concentration (7-38\%) of insoluble-bound phenolics (Nayak et al., 2015; Sun and Cheng, 2002).

So far, the antioxidant potential of lentil cultivars such as free radical scavenging ability, metal chelation, and oxygen radical absorbance capacity (ORAC) has been well established in other studies, however, there is dearth information on the inhibitory activity of soluble- and insoluble-bound phenolics in lentils against oxidation of LDL cholesterol and DNA strand breakage. Therefore, this study evaluated and compared phenolic contents between the hulls and dehulled grains in lentil cultivars as well as assessing their $\alpha$-glucosidase inhibitory activity. 


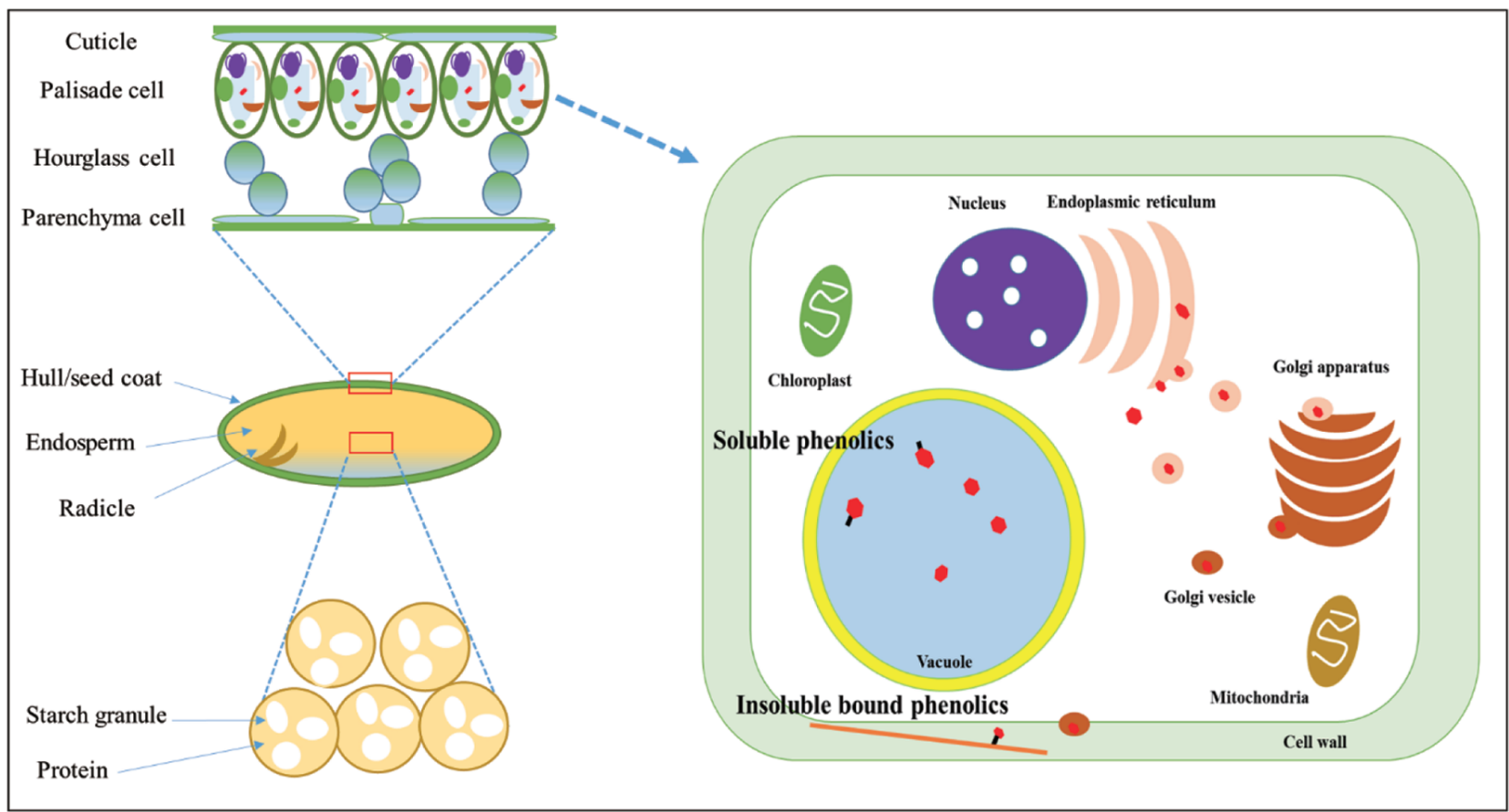

Figure 1. The microstructure of lentil and localization of soluble- and insoluble-bound phenolics in plant cells.

\section{Materials and methods}

\subsection{Materials}

Lentils cultivars were provided by Professor Albert (Bert) Vandenberg of the experimental farm of the University of Saskatchewan, Saskatoon, SK, Canada. Organic solvents such as hexane, methanol, ethanol, and acetone were purchased from Fisher Scientific Co. (Nepean, ON, Canada). Chemicals used for the antioxidant capacity and bioactivity such as Folin Ciocalteau's reagent, gallic acid, and catechin were purchased from Sigma-Aldrich Canada Ltd. (Oakville, ON, Canada). Mono- and dibasic potassium phosphate, ferrous sulphate $\left(\mathrm{FeSO}_{4}\right)$, human low-density lipoprotein (hLDL), pBR 322 plasmid DNA, Tris acetate, agarose, bromophenol blue, glycerol, and xylene cyanol were obtained from SigmaAldrich Canada Ltd. SYBR safe gel stain was purchased from Probes Invitrogen (Eugene, OR, USA).

\subsection{Dehulling of lentils}

Lentils were cleaned thoroughly to remove any extraneous particles. Dehulling process employed was according to the procedure described by Chandrasekara et al. (2012).

\subsection{Extraction of soluble phenolics (SPs) and insoluble-bound phenolics (IBPs)}

The procedure followed for the extraction of SPs and IBPs was as described by Yeo and Shahidi (2020). Prior to the extraction, hulls and dehulled grains of lentils were defatted by using n-hexane. For the extraction of SPs, defatted hulls and dehulled lentils $(1.0 \mathrm{~g})$ was mixed with $10 \mathrm{~mL}$ of extraction medium composed of metha- nol/acetone/water $(1: 1: 1, \mathrm{v} / \mathrm{v} / \mathrm{v})$, followed by $20 \mathrm{~min}$ of standing at room temperature. This procedure was repeated another two times more and the combined extracts were kept in one vial. The residue after extraction of SPs was used for the extraction of IBPs. Briefly, $1 \mathrm{~g}$ of the residue was blended with $15 \mathrm{~mL}$ of $2 \mathrm{M} \mathrm{NaOH}$ which was subsequently allowed to stand for $4 \mathrm{~h}$ while stirring. The alkali hydrolyzed samples were mixed with $4.63 \mathrm{~mL}$ of $6 \mathrm{M} \mathrm{HCl}$ to reach $\mathrm{pH}<2$ for better extraction of the liberated phenolics. Subsequently, the released phenolics were extracted with ethyl acetate five times. After that, the solvent ethyl acetate was removed using a rotary evaporator, followed by dissolving in $10 \mathrm{~mL}$ of methanol.

\subsection{Total phenolic content (TPC)}

Total phenolic content of lentils was determined as described by Chandrasekara and Shahidi (2010) with minor modifications. An aliquot $(125 \mu \mathrm{L})$ of each sample was mixed with $2 \mathrm{~mL}$ of distilled water and $63 \mu \mathrm{L}$ of Folin-Ciocalteu reagent. Subsequently, the mixtures were allowed to react with $250 \mu \mathrm{L}$ of $7 \%$ sodium carbonate and then kept in the dark for 30 min at ambient temperature. The absorbance of the final solution was read at $725 \mathrm{~nm}$ and expressed as mg gallic acid equivalents /g of DW.

\subsection{Total flavonoid content (TFC)}

Total flavonoid content was measured as described by Chandrasekara and Shahidi (2010) with slight modification. Briefly, 0.5 $\mathrm{mL}$ of lentil extract $(20 \mathrm{mg} / \mathrm{mL})$ was dissolved in $2 \mathrm{~mL}$ of distilled water and then $0.15 \mathrm{~mL}$ of $5 \% \mathrm{NaNO}_{2}$ was added. After standing for $5 \mathrm{~min}$, the samples were allowed to react with $0.15 \mathrm{~mL}$ of $10 \%$ $\mathrm{AlCl}_{3}$ and $1 \mathrm{~mL}$ of $1 \mathrm{M} \mathrm{NaOH}$ for $15 \mathrm{~min}$ in the dark. The absorbance was recorded at $510 \mathrm{~nm}$ and total flavonoid content was expressed as mg catechin equivalents (CE) /g of DW. 


\subsection{Cupric ion-induced human low-density lipoprotein (LDL) peroxidation}

The inhibitory activity of human LDL peroxidation induced by cupric ion was evaluated according to the method described by Alshikh et al. (2015). In order to remove EDTA dissolved in LDL cholesterol, LDL was dialyzed using $10 \mathrm{mM}$ phosphate buffer $(\mathrm{pH}$ $7.4,0.15 \mathrm{M} \mathrm{NaCl}$ ) at $4{ }^{\circ} \mathrm{C}$ under a nitrogen blanket in the dark for 12 h. For assessing inhibitory activity against LDL oxidation, $0.8 \mathrm{~mL}$ of LDL cholesterol $(0.04 \mathrm{mg} \mathrm{LDL} / \mathrm{mL})$ was mixed with $0.1 \mathrm{~mL}$ of soluble- and insoluble-bound phenolics in hulls and dehulled grains of lentils and subsequently pre-incubated at $37^{\circ} \mathrm{C}$ for $15 \mathrm{~min}$. After that, $0.1 \mathrm{~mL}$ of cupric sulphate $(50 \mu \mathrm{M})$ was added to the mixture and incubated at $37^{\circ} \mathrm{C}$ for $11 \mathrm{~h}$. The conjugated dienes (CD) from the oxidation of LDL cholesterol was read at $234 \mathrm{~nm}$ using a diode array spectrophotometer (Agilent, Palo Alto, CA, USA).

\subsection{Inhibition of peroxyl and hydroxyl radical-induced super- coiled DNA strand scission}

Inhibitory activity against DNA strand scission induced by peroxyl and hydroxyl radicals of phenolics from lentils was measured according to the method described by Chandrasekara and Shahidi (2011). First, DNA strand $(50 \mu \mathrm{g} / \mathrm{mL})$, which was dissolved in 10 $\mathrm{mM}$ phosphate buffer (PBS, pH 7.4), was mixed with PBS $(2 \mu \mathrm{L})$, pBR $322(50 \mu \mathrm{g} / \mathrm{mL}, 2 \mu \mathrm{L})$, and $4 \mu \mathrm{L}$ of $7 \mathrm{mM}$ 2,2'-azobis (2-methylpropanimidamide dihydrochloride (AAPH); phenolics extracted from lentils $(0.1 \mathrm{mg} / \mathrm{mL}, 2 \mu \mathrm{L})$ was used to evaluate the inhibitory activity of phenolics against peroxyl radical induced oxidation. In addition, phenolics $(6 \mathrm{mg} / \mathrm{mL}, 2 \mu \mathrm{L})$, PBS $(2 \mu \mathrm{L}), \mathrm{pBR} 322(50 \mu \mathrm{g} / \mathrm{mL}$, $2 \mu \mathrm{L}), \mathrm{FeSO}_{4}(0.5 \mathrm{mM}, 2 \mu \mathrm{L})$, and $\mathrm{H}_{2} \mathrm{O}_{2}(0.5 \mathrm{mM}, 2 \mu \mathrm{L})$ were mixed and incubated at $37{ }^{\circ} \mathrm{C}$ for $1 \mathrm{~h}$ for hydroxyl radical-induced oxidation. After incubation, $1 \mu \mathrm{L}$ of dye $(0.25 \%$ bromophenol blue, $0.25 \%$ xylene cyanol, and 50\% glycerol) was blended with the reaction mixture. Then, $10 \mu \mathrm{L}$ of the resultant solution was loaded onto $0.7 \%$ agarose gel solution (prepared in Tris-acetic acid-EDTA (TAE) buffer (40 mM Tri-acetate containing $1 \mathrm{mM}$ EDTA, $\mathrm{pH} 8.5$ ), followed by the addition of SYBR safe $(5 \mu \mathrm{L})$ into agarose gel solution $(50 \mathrm{~mL})$ as a gel stain. The analysis of electrophoresis was carried out using a model B1A horizontal mini gel electrophoresis system (Owl Separation Systems Inc., Portsmonth, NH, USA) and a model $300 \mathrm{~V}$ power supply (VWR International Inc., West Chester, PA, USA) in TAE buffer. The reading of intensity (area \%) of bands was conducted using the Chemi-Imager 4400 software (Cell Biosciences).

\section{8. $\alpha$-Glucosidase inhibitory activity}

$\alpha$-Glucosidase inhibitory activity was determined according to Liu et al. (2011) with slight modification. The $\alpha$-glucosidase (rat intestine) concentration $(10 \mathrm{U} / \mathrm{mL})$ was dissolved in $20 \mathrm{mM}$ of sodium phosphate buffer ( $\mathrm{pH}$ 6.8). In a test tube, $5 \mu \mathrm{L}$ of $\alpha$-glucosidase solution was mixed with $10 \mu \mathrm{L}$ of phenolics and $620 \mu \mathrm{L}$ of PBS, followed by pre-incubation at $37^{\circ} \mathrm{C}$ in an oven for $20 \mathrm{~min}$. The mixture was allowed to react with $10 \mu \mathrm{L}$ of $10 \mathrm{mM} p$-nitrophenyl$\alpha$-D-glucopyranoside (PNPG) solution and incubated at $37^{\circ} \mathrm{C}$ for another $20 \mathrm{~min}$. The reaction was terminated by adding $650 \mu \mathrm{L}$ of $1 \mathrm{M} \mathrm{Na}_{2} \mathrm{CO}_{3}$, and absorbance was recorded at $410 \mathrm{~nm}$.

\subsection{Statistical analysis}

The data from three independent replicates were subjected to one- way ANOVA. The mean was separated by Tukey's HSD test $(p<$ 0.05 ) using SPSS 16.0 for Windows (SPSS Inc., Chicago, IL, USA).

\section{Results and discussion}

\subsection{Total phenolic content (TPC) and total flavonoid content (TFC)}

Total phenolic content (TPC) was determined using Folin Ciocalteu's reagent for lentil cultivars and the results were expressed as $\mathrm{mg}$ gallic acid equivalents (GAE)/g of DW (Table 1). In hulls, the range of TPC in SPs was 31.5-33.6 mg GAE/g and the corresponding IBPs were 19.7-24.3 mg GAE/g, showing a higher TPC of SPs than IBPs. On the other hand, the dehulled lentil grains showed significantly lower TPC values than the corresponding hulls of lentils. Thus, the soluble phenolics of dehulled grains was $1.6 \mathrm{mg} \mathrm{GAE} / \mathrm{g}$ of DW in four lentil cultivars and 1.0-1.2 mg GAE in the insoluble-bound phenolics. This result indicates the biased distribution of phenolics in lentils. Therefore, both SPs and IBPs were more abundant in hulls than in the dehulled grains. This uneven distribution of phenolics has been well documented in pulses in the literature. For example, Das and Singh (2016) reported that maize possessed $282.5 \mu$ mole ferulic acid equivalent (FAE) $/ \mathrm{g}$ of dried hulls, respectively, while a total of only $5.4 \mathrm{FAE} / \mathrm{g}$ was found in the endosperm. This supports the biased distribution of phenolics toward the hull portion than in the dehulled fraction in pulses. Some studies have shown a lower TPC in whole lentils than their hulls. For example, Alshikh et al. (2015) investigated TPC in whole seeds of six lentil cultivars and the range of TPC in SPs was 3.6-27.0 and 1.2-17.5 mg GAE/g DW in IBPs. Moreover, Xu and Chang (2008) reported that the range of TPCs in lentils was 4.9-9.6 $\mathrm{mg} \mathrm{GAE} / \mathrm{g}$, which is lower than the TPC of hulls in the present study. These reports also support the biased distribution of phenolics toward hulls than in the dehulled grains of pulses.

Meanwhile, the ratios of IBPs to SPs in the hulls and dehulled grains of lentil cultivars are summarized in Table 1. This concept was first suggested in our previous study as an efficient indicator for the prediction of changes in the formation of phenolics from soluble into insoluble-bound form during germination (Yeo and Shahidi, 2015). The range of this ratio was from 0.6 to 0.8 in four lentil cultivars in both hulls and dehulled grains, indicating that a high percentage of phenolics was present in the soluble form than in the insoluble-bound form in both hulls and dehulled grains of lentils.

Total flavonoid content of soluble- and insoluble-bound phenolics of four lentil cultivars showed a similar tendency to the total phenolic content (Table 1). Thus, the ranges of flavonoids as soluble- and insoluble-bound form were 1.1-1.2 and 0.7-0.9 mg CE/g in dehulled lentils, respectively, also showing a biased distribution of phenolics in the hulls than in the dehulled grain fraction.

Overall, phenolics were more abundant in hulls as shown in the total phenolic and total flavonoid contents. The dominance of phenolics to the hulls compared to the dehulled grains might be due to their physical structure and the difference in the composition of cells. As described in Figure 1, the hull fraction in grains consists of diverse types of cells such as palisade, hourglass, and parenchyma cells which have phenolic-containing organs such as vacuoles where most soluble phenolics occur and cell wall matrix having insoluble-bound phenolics. Conversely, a large portion of dehulled grain is filled with nutrition-storage organs such as endosperm. The endosperm is responsible for storing energy sources such as starch, proteins, and lipids and not the phenolic-containing organs such as vacuoles. Therefore, the different composition of 
Table 1. Total phenolic and total flavonoid content of SPs and IBPs in hulls and dehulled grains of lentils

\begin{tabular}{|c|c|c|c|c|c|c|c|c|}
\hline & \multicolumn{8}{|c|}{ Total phenolic content (Gallic acid equivalents, mg/g DW) } \\
\hline & \multicolumn{4}{|c|}{ Hull } & \multicolumn{4}{|c|}{ Dehulled } \\
\hline & SPs & IBPs & Total & Ratio (IBPs/SPs) & SPs & IBPs & Total & Ratio (IBPs/SPs) \\
\hline Greenland & $32.8 \pm 0.3 b$ & $19.7 \pm 0.2 d$ & 52.5 & 0.6 & $1.6 \pm 0.0 \mathrm{a}$ & $1.1 \pm 0.0 b$ & 2.7 & 0.7 \\
\hline 3494 & $33.6 \pm 0.1 a$ & $23.1 \pm 0.2 b$ & 56.7 & 0.7 & $1.6 \pm 0.0 a$ & $1.0 \pm 0.0 a$ & 2.6 & 0.6 \\
\hline Invincible & $32.5 \pm 0.3 b$ & $24.3 \pm 0.1 a$ & 56.8 & 0.8 & $1.6 \pm 0.0 \mathrm{a}$ & $1.2 \pm 0.0 \mathrm{~b}$ & 2.8 & 0.7 \\
\hline \multirow[t]{4}{*}{ Maxim } & $31.5 \pm 0.1 c$ & $22.4 \pm 0.2 c$ & 53.8 & 0.7 & $1.6 \pm 0.1 \mathrm{a}$ & $1.0 \pm 0.0 a$ & 2.6 & 0.6 \\
\hline & \multicolumn{8}{|c|}{ Total flavonoid content (Catechin equivalents, $\mathrm{mg} / \mathrm{g}$ DW) } \\
\hline & \multicolumn{4}{|c|}{ Hull } & \multicolumn{4}{|c|}{ Dehulled } \\
\hline & SPs & IBPs & Total & Ratio (IBPs/SPs) & SPs & IBPs & Total & Ratio (IBPs/SPs) \\
\hline Greenland & $7.4 \pm 0.5 b c$ & $11.0 \pm 0.0 d$ & 18.4 & 1.5 & $1.1 \pm 0.1 \mathrm{a}$ & $0.8 \pm 0.1 a$ & 2.5 & 0.8 \\
\hline 3494 & $7.9 \pm 0.1 \mathrm{ab}$ & $13.0 \pm 0.3 b$ & 20.9 & 1.6 & $1.2 \pm 0.1 \mathrm{a}$ & $0.9 \pm 0.1 \mathrm{a}$ & 2.8 & 0.7 \\
\hline Invincible & $8.4 \pm 0.1 a$ & $14.7 \pm 0.1 \mathrm{a}$ & 23.1 & 1.7 & $1.1 \pm 0.1 \mathrm{a}$ & $0.8 \pm 0.1 \mathrm{ab}$ & 2.8 & 0.8 \\
\hline Maxim & $7.2 \pm 0.0 c$ & $12.7 \pm 0.1 b$ & 19.9 & 1.7 & $1.2 \pm 0.1 \mathrm{a}$ & $0.7 \pm 0.1 b$ & 2.9 & 0.6 \\
\hline
\end{tabular}

Values in each column having the same letter are not significantly different $(p>0.05)$.

cells in hulls and dehulled grains might be a primary reason for the biased distribution of phenolics in lentil cultivars tested.

\subsection{Inhibitory activity of soluble- and insoluble-bound pheno- lics in hulls and dehulled grains of lentils against oxidation of LDL cholesterol}

LDL cholesterol performs a key function in transporting lipids to the cell body by acting as a shuttle. Nevertheless, they are referred to as "bad cholesterol" since they cause cardiovascular disease. The oxidation of LDL cholesterol in the bloodstream accelerates the accumulation of the proteoglycan-oxLDL complex at the arterial wall. This leads to a narrowing of the blood vessel and can block the bloodstream. Thus, preventing the oxidation of LDL cholesterol is extremely important for reducing the incidence of vascular diseases. In the present study, the LDL cholesterol oxidation inhibitory activities of soluble- and insoluble-bound phenolics in hulls and dehulled lentils were determined (see Figure 2). According to the results, the dehulled grains of lentils in both soluble- and insoluble-bound phenolic fractions showed a decrease in absorbance at $234 \mathrm{~nm}$ after $3 \mathrm{~h}$ of incubation, which is not observed in the hulls. The decrease of absorbance might be due to the loss of phenolics since absorbance at $234 \mathrm{~nm}$ is partially derived from phenolics, as can be seen in the absorbance at $0 \mathrm{~h}$ of incubation in Figure 2. Therefore, the oxidation of LDL cholesterol is calculated after $3 \mathrm{~h}$ of incubation because the changes in absorbance are not induced by the formation of conjugated dienes from the oxidation of LDL cholesterol. Absorbance at $234 \mathrm{~nm}$ of the control (LDL cholesterol without phenolics) was increased from 0.504 ( $3 \mathrm{~h}$ ) to $0.653(11 \mathrm{~h})$, an increase of $0.149 \mathrm{in}$ absorbance, indicating the formation of conjugated dienes during the oxidation of LDL cholesterol. The structure of LDL cholesterol consists of an outer surface that is mainly phospholipids and lipoproteins and an inner space packed with cholesterol, cholesterol-esters, and triacylglycerols. Therefore, the production of conjugated dienes in the oxidation of LDL cholesterol might come from the oxidation of phospholipids, cholesterol-esters and triacylglycerols.
In the soluble phenolics of hulls, the absorbances of Greenland, 3494-6, Invincible, and Maxim were increased by $0.115,0.099$, 0.117 , and 0.121 during the $11 \mathrm{~h}$ of incubation, respectively, corresponding to $23,22,21$, and $18 \%$ of inhibition against the oxidation of LDL cholesterol compared to the control (an increase of 0.149). In the same way, insoluble-bound phenolics in the hulls of lentils also attenuated the oxidation of LDL particles by $16-32 \%$ during LDL oxidation. On the other hand, the dehulled grains of lentils did not show any inhibitory activity against the oxidation of LDL cholesterol. This might be due to the difference in the level of phenolics in hulls and dehulled grains of lentils as discussed for TPC and TFC. Chandrasekara and Shahidi (2011) studied the inhibitory activities of hulls and dehulled grains of millets against the oxidation of LDL cholesterol and reported a better inhibitory activity of hulls than the corresponding dehulled grains, which strongly supports the results of the present study. Ranilla et al. (2007) also found that polyphenols of Brazilian and Peruvian Bean Cultivars (Phaseolus vulgaris L.) were present mainly in seed coat as compared to the cotyledon.

\subsection{DNA scission inhibitory activities of soluble-and insoluble- bound phenolics in hulls and the dehulled lentil grains}

The oxidation of DNA strand is responsible for the mutation of cells and can lead to serious adult diseases such as cancer. Thus, the oxidation of DNA strand should be prevented to maintain the health of the cells. In the present study, we investigated the inhibitory activities of soluble- and insoluble-bound phenolics in hulls and dehulled lentils against the oxidation of DNA strand, as summarized in Table 2. Figure 3 clearly shows the stronger inhibitory activity of (insoluble-bound) phenolics in hulls compared to the corresponding dehulled grains of lentils. In both hydroxyl radicaland peroxyl radical-induced oxidation, hulls showed much higher inhibitory activity than the dehulled grains; namely, hulls showing $41-54 \%$ of inhibitory activity in soluble phenolics and $58-65 \%$ of inhibition in insoluble-bound phenolics upon hydroxyl radical induce oxidation. On the other hand, dehulled grain fractions showed a 

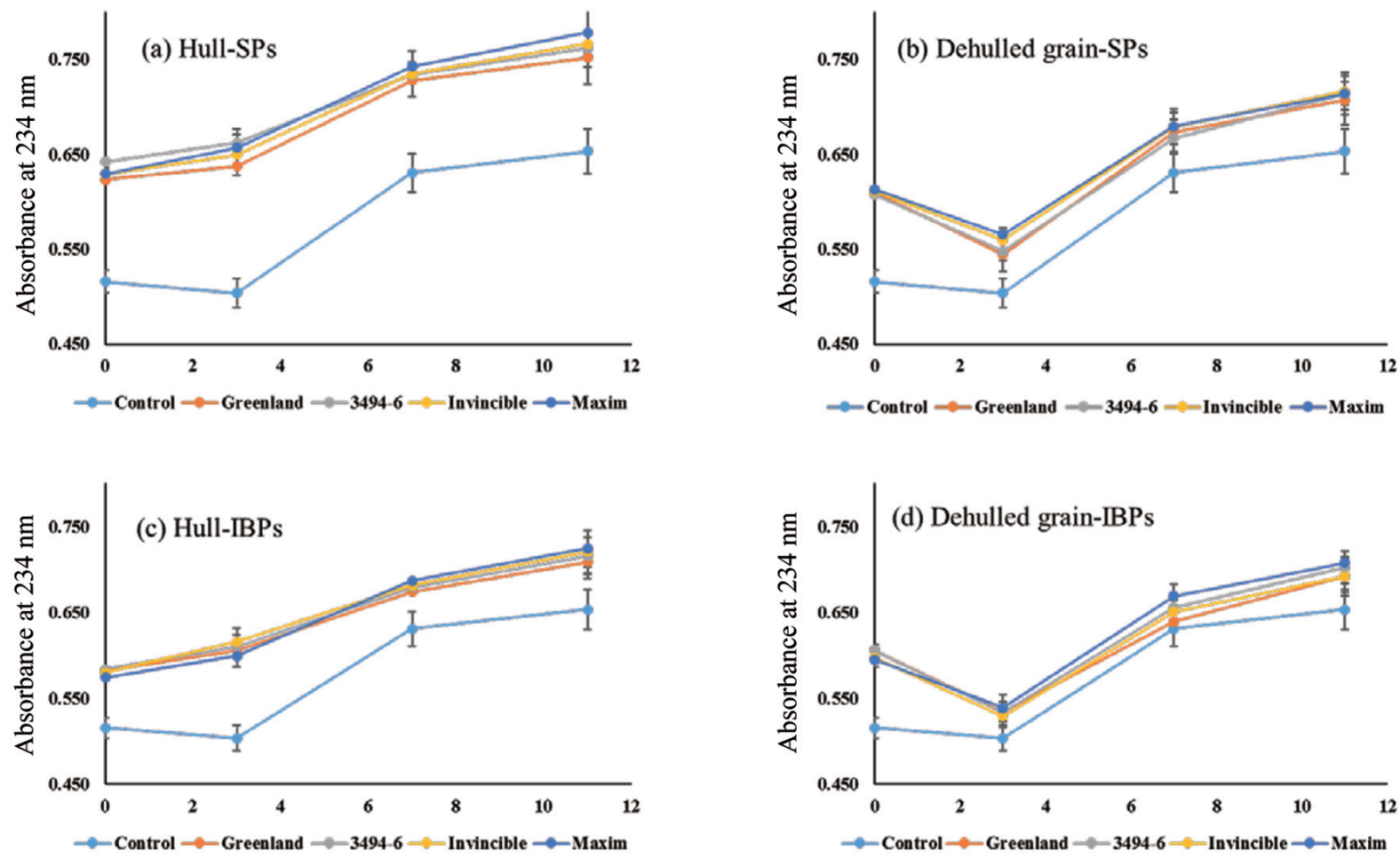

Figure 2. LDL oxidation inhibitory activity of soluble- and insoluble-bound phenolics in hulls and dehulled grains of lentils.

relatively lower inhibitory activity against DNA oxidation than their corresponding hulls by displaying $20-44 \%$ inhibition in soluble phenolics and $32-52 \%$ in insoluble-bound phenolics. In the peroxyl radical-induced oxidation, similar trends were observed with a better inhibitory activity in hulls than the dehulled grains. Chandrasekara and Shahidi (2011) investigated the inhibitory activity of millet hulls and dehulled millets against oxidation of DNA strand; they reported a higher inhibitory activity of hulls than the corresponding dehulled grains, which agrees with the results of the present study.
In intracellular spaces, reactive oxygen species (ROS) are simultaneously produced at the mitochondria through Fenton's reaction, and they perform an essential role by acting as a signalling molecule. However, the overproduction of ROS in cells can cause oxidative stress, thus leading to the oxidation of DNA. Therefore, dietary antioxidant supplementation has been suggested for maintaining the balance between ROS and antioxidants in the cells. In this regard, it is expected that lentils could serve as a suitable natural source of antioxidants.

Table 2. The DNA scission inhibitory activity of phenolics in hulls and dehulled grains of lentils

\begin{tabular}{|c|c|c|c|c|}
\hline & \multicolumn{4}{|c|}{ Hydroxyl radical-induced oxidation (inhibition \%) } \\
\hline & \multicolumn{2}{|c|}{ Hulls } & \multicolumn{2}{|c|}{ Dehulled } \\
\hline & SPs & IBPs & SPs & IBPs \\
\hline Greenland & $43 \pm 8 a$ & $65 \pm 4 a$ & $31 \pm 4 b$ & $52 \pm 14 a$ \\
\hline 3494 & $45 \pm 9 a$ & $65 \pm 7 a$ & $30 \pm 2 b c$ & $45 \pm 15 a$ \\
\hline Invincible & $41 \pm 13 a$ & $58 \pm 6 a$ & $44 \pm 5 a$ & $48 \pm 11 a$ \\
\hline \multirow[t]{4}{*}{ Maxim } & $54 \pm 2 a$ & $63 \pm 6 a$ & $20 \pm 2 c$ & $30 \pm 5 a$ \\
\hline & \multicolumn{4}{|c|}{ Peroxyl radical-induced oxidation (inhibition \%) } \\
\hline & \multicolumn{2}{|c|}{ Hulls } & \multicolumn{2}{|c|}{ Dehulled } \\
\hline & SPs & IBPs & SPs & IBPs \\
\hline Greenland & $97 \pm 1 a$ & $97 \pm 8 a$ & $67 \pm 2 a$ & $24 \pm 1 \mathrm{a}$ \\
\hline 3494 & $99 \pm 4 a$ & $98 \pm 6 a$ & $60 \pm 1 a b$ & $18 \pm 3 a$ \\
\hline Invincible & $97 \pm 0 a$ & $95 \pm 4 a$ & $59 \pm 3 a b$ & $19 \pm 8 a$ \\
\hline Maxim & $97 \pm 1 a$ & $95 \pm 4 a$ & $53 \pm 6 b$ & $10 \pm 8 a$ \\
\hline
\end{tabular}



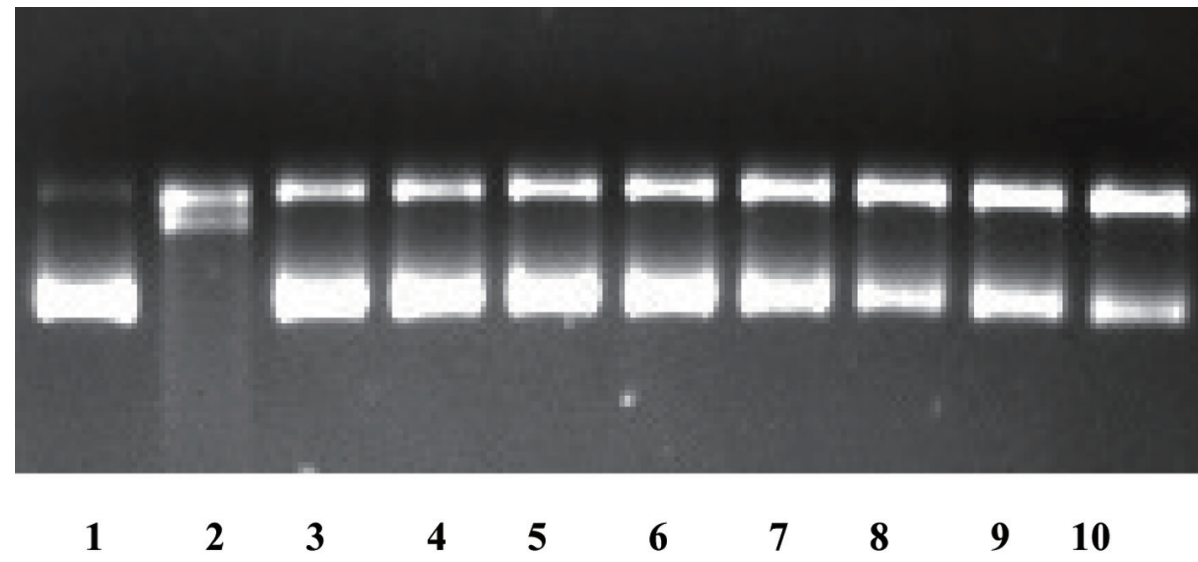

Figure 3. The DNA scission inhibitory activity of insoluble-bound phenolics of hulls and dehulled grains of lentils at the hydroxyl radical oxidation system (1 blank; 2 control; 3 Greenland hulls; 43494 hulls; 5 Invincible hulls; 6 Maxim hulls; 7 Greenland dehulled; 83494 dehulled; 9 Invincible dehulled; and 10 Maxim dehulled).

\section{4. $\alpha$-Glucosidase inhibitory activity of phenolics in hulls and dehulled grains of lentils}

$\alpha$-Glucosidase is involved in the hydrolysis of polysaccharides into simple sugars, thus facilitating the supplement of energy to the cells. However, a high activity of $\alpha$-glucosidase harms the patients who suffer from diabetes since the enzyme yields more sugar and increases the level of blood sugar in the patients. Therefore, the inhibition of enzyme activity of $\alpha$-glucosidase is important for both reducing complications of the patients who are suffering type-2-diabetes and preventing the incidence of type-2-diabetes. The $\alpha$-glucosidase inhibitory activities of soluble- and insolublebound phenolics in hulls and dehulled grains of lentils were measured and the results are shown in Figure 4. The soluble phenolics in hulls showed a much higher $\alpha$-glucosidase inhibitory activity than the corresponding dehulled grains; soluble phenolics in hulls reduced $62-75 \%$ of its activity while dehulled grains did not inhibit $\alpha$-glucosidase activity. Similar results were also found for the insoluble-bound phenolics; hulls of lentil cultivars attenuated $\alpha$-glucosidase activity about $45-80 \%$ whereas dehulled grains did not show any inhibitory activity, except for Maxim (23\%). Overall, hulls in both soluble- and insoluble-phenolics showed a higher $\alpha$-glucosidase inhibitory activity than the corresponding dehulled grains. This might be due to the discrepancy in the localization of phenolics in the structure of lentils.

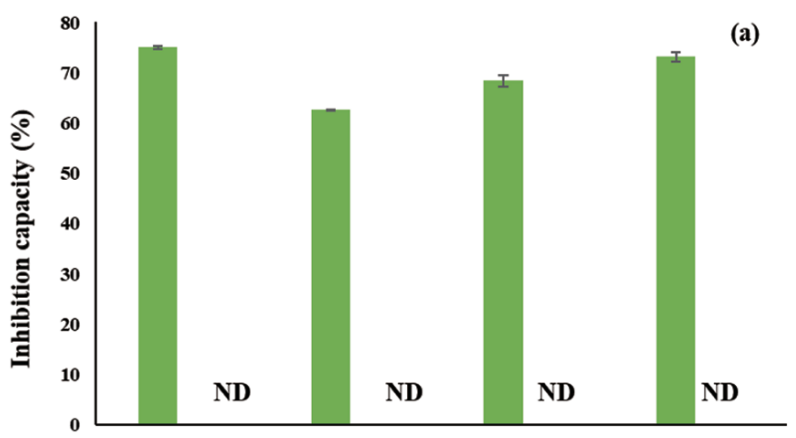

\section{Conclusion}

In the present study, antioxidant potentials of soluble- and insoluble-bound phenolics from hulls and dehulled grains of lentils and their other bioactivities were evaluated. In all measurements, hulls in both soluble- and insoluble-phenolics showed higher antioxidant and other bioactivities than the corresponding dehulled grains of lentils. The different composition of cells in hulls and dehulled grains might be a primary reason for the biased distribution of phenolics in the tested lentil cultivars. Thus, the hulls of lentil cultivars serve as an excellent source of soluble- and insoluble-bound phenolics and have the potential to serve as a source of nutraceutical and functional food ingredients.

\section{Acknowledgments}

We are grateful to the Natural Science and Engineering Council (NSERC) of Canada in the form of a discovery grant to FS.

\section{References}

Alshikh, N., de Camargo, A., and Shahidi, F. (2015). Phenolics of selected lentil cultivars: Antioxidant activities and inhibition of low-density li-

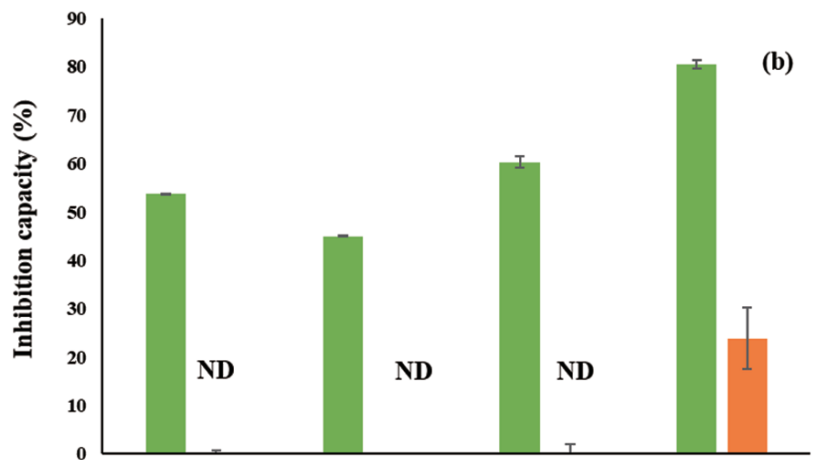

Figure 4. $\alpha$-Glucosidase inhibitory activity of soluble- (a) and insoluble-bound phenolics (b) in hulls (Green) and dehulled grains (Orange) in lentil cultivars; ND: Not detected. 
poprotein and DNA damage. J.Funct. Foods 18: 1022-1038.

Amit, K., Das, A.K., and Singh, V. (2016). Antioxidative free and bound phenolic constituents in botanical fractions of Indian specialty maize (Zea mays L.) genotypes. Food Chem. 201: 298-306.

Boudjou, S., Oomah, B.D., Zaidi, F., and Hosseinian, F. (2013). Phenolics content and antioxidant and anti-inflammatory activities of legume fractions. Food Chem. 138: 1543-1550.

Chandrasekara, A., and Shahidi, F. (2011). Bioactivities and antiradical properties of millet grains and hulls. J. Agric. Food Chem. 59: 95639571.

Chandrasekara, A., and Shahidi, F. (2010). The content of insoluble bound phenolics in millets and their contribution to antioxidant capacity. J. Agric. Food Chem. 58: 6706-6714.

Chandrasekara, A., Naczk, M., and Shahidi, F. (2012). Effect of processing on the antioxidant activity of millet grains. Food Chem. 133: 1-9.

Das, A.K., and Singh, V. (2016). Antioxidative free and bound phenolic constituents in botanical fractions of Indian specialty maize (Zea mays L.) genotypes. Food Chem. 201: 298-306.

De Mejia, E., Guzman-Maldonado, S.H., Acosta-Gallegos, J.A., Pons-Hernandez, J.L., Gonzalez-Chavira, M.M., and Castellanos, J.Z. (2003). Effect of cultivar and growing location on the trypsin inhibitors, tannins, and lectins of common beans (Phaseolus vulgaris L.) grown in the Semiarid Highlands of Mexico. J. Agric. Food Chem. 51: 5962-5966.

Eitsuka, T., Tatewaki, N., Nishida, H., Kurata, T., Nakagawa, K., and Miyazawa, T. (2014). Synergistic inhibition of cancer cell proliferation with a combination of delta-tocotrienol and ferulic acid. Biochem. Biophys. Res. Commun. 453: 606-611.

Ranilla, L.G., Genovese, M.I., and Lajolo, F.M. (2007). Polyphenols and antioxidant capacity of seed coat and cotyledon from Brazilian and Peruvian bean cultivars (Phaseolus vulgaris L.). J. Agric. Food Chem. 55: 90-98.

Hsu, W.C., Chang, S.P., Lin, L.C., Li, C.L., Richardson, C.D., Lin, C.C., and Lin, L.T. (2015). Limonium sinense and gallic acid suppress hepatitis $C$ virus infection by blocking early viral entry. Antiviral Res. 118: 139-147.

Liu, T., Song, L., Wang, H., and Huang, D. (2011). A high-throughput assay for quantification of starch hydrolase inhibition based on turbidity measurement. J. Agric. Food Chem. 59: 9756-9762.

Mancuso, C., and Santangelo, R. (2014). Ferulic acid: Pharmacological and toxicological aspects. Food Chem. Toxicol. 65: 185-195.

Morgan, R.L., Baack, B., Smith, B.D., Yartel, A., Pitasi, M., and Falck-Ytter, Y. (2013). Eradication of hepatitis $C$ virus infection and the development of hepatocellular carcinoma: a meta-analysis of observational studies. Ann. Intern. Med. 158: 329-337.

Narasimhan, A., Chinnaiyan, M., and Karundevi, B. (2015). Ferulic acid regulates hepatic GLUT2 gene expression in high fat and fructoseinduced type-2 diabetic adult male rat. Eur. J. Pharmacol. 761: 391397.

Nayak, B., Liu, R.H., and Tang, J. (2015). Effect of processing on phenolic antioxidants of fruits, vegetables and grains: A review. Critic. Rev. Food Sci. Nutr. 55: 887-918.

Osman, A.G., Elaziz, F.I.A., and Elhassan, G.A. (2010). Effects of biological and mineral fertilization on yield, chemical composition and physical characteristics of faba bean (Vicia faba L.) cultivar Saleim. Pak. J. Nutr. 9: 703-708.

Rochfort, S., and Panozzo, J. (2007). Phytochemicals for health, the role of pulses. J. Agric. Food Chem. 55: 798-7994.

Shahidi, F., Liyana-Pathirana, C.M., and Wall, D.S. (2006). Antioxidant activity of white and black sesame seeds and their hull fractions. Food Chem. 99: 478-483.

Sun, Y., and Cheng, J. (2002). Hydrolysis of lignocellulosic materials for ethanol production: A review. Biores. Technol. 82: 1-11.

Tian, Y., Jiang, Y., and Ou, S. (2013). Interaction of cellulase with three phenolic acids. Food Chem. 138: 1022-1027.

Xu, B., and Chang, S.K.C. (2008). Effect of soaking, boiling, and steaming on total phenolic content and antioxidant activities of cool season food legumes. Food Chem. 110: 1-13.

Yeo, J.D., and Shahidi, F. (2015). Critical evaluation of changes in the ratio of insoluble bound to soluble phenolics on antioxidant activity of lentils during germination. J. Agric. Food Chem. 63: 379-381.

Yeo, J.D., and Shahidi, F. (2020). Identification and quantification of soluble and insoluble-bound phenolics in lentil hulls using HPLC-ESI-MS/MS and their antioxidant potential. Food Chem. 315: 126202. 